MENTAL HEALTHLAW PROFILE

\title{
The draft Mental Health Act in Sudan
}

\author{
Mahmoud Saeed, ${ }^{1}$ Saoud Sultan ${ }^{2}$ and Abdelazim Ali ${ }^{3}$
}

${ }^{1}$ Consultant Psychiatrist, Birmingham and Solihull Mental Health NHS Foundation Trust, UK Health NHS Foundation Trust, UK ${ }^{2}$ Consultant Psychiatrist and College Tutor, North East London NHS Foundation Trust, UK

${ }^{3}$ Aneurin Bevan Health Board, UK email abdelazimali@hotmail.com
At a workshop in 2012 in Khartoum, attended by Sudanese psychiatrists based in both the UK and Sudan, as well as psychologists, social workers and lawyers from Sudan and elsewhere, a draft Mental Health Act for Sudan was approved; it is due to be submitted to the Sudanese Parliament. We give a summary of the draft Act and outline some of the areas that need further discussion.

Sudan was a pioneer in developing mental health services. The first Black African to be awarded the UK Diploma in Psychological Medicine was from Sudan - Eltigani Elmahi, in 1949. He returned to Khartoum and in 1951 established the first psychiatric out-patient clinic in sub-Saharan Africa. In the following 60 years the country was ravaged by the longest civil war in Africa, which culminated in the secession of the southern part of the country to form the independent South Sudan in 2011 (not considered in this article). This led to significant deterioration in public services in general. Mental health services are now concentrated in the big cities of Sudan and vast areas of the country have few services or none at all.

Sudanese psychiatrists continued with their efforts to improve the mental health services. In the absence of any formal powers for health professionals, psychiatric patients are currently brought to hospital by their relatives, who generally have to remain in the hospital to ensure that patients adhere to their treatment plan and do not leave the hospital against medical advice.

In 1997 a Mental Health Act had been drafted, but this was not followed up by the health authorities. In 2012, the Sudanese government asked the Sudanese Psychiatrists Association to prepare a new draft Act. A draft was prepared and discussed at a special workshop organised by the Sudanese Psychiatrists Association, in collaboration with its sister organisation, the Sudanese Psychiatrists Association (UK and Ireland). Sudanese psychiatrists from around the world gathered in Khartoum in December 2012 and agreed on the final draft. This will eventually be submitted to the Sudanese Parliament for approval.

The new draft Mental Health Act consists of seven chapters.

\section{Chapter 1. Preliminary provisions and definitions}

This chapter is about definitions and the application of the Act. The Act uses the World Health Organization's definition of mental health as 'a state of well-being in which every individual realizes his or her own potential, can cope with the normal stresses of life, can work productively and fruitfully, and is able to make a contribution to her or his community' (see e.g. http://www. who.int/features/factfiles/mental_health/en/). The Act defines the patient as 'a person suffering from a mental disorder'. The mental disorder is defined as 'any complete or partial disturbance in thinking, behaviour, mood, cognition, memory or mental ability', and this 'should not include any behaviour [that is merely] contrary to customs and traditions' or 'abuse of or dependence on alcohol or illicit substances, unless it is associated with mental disorder'.

\section{Chapter 2. Principles and objectives}

This chapter outlines the main principles and aims of the law, including the rights of people who suffer from a mental disorder to receive the best available psychiatric care.

\section{Chapter 3. Licence and mental health councils}

This chapter is mainly about the proposed National Mental Health Council and its branches in the different states of Sudan. The role of the Council will be to regulate the profession and issue licences to practise.

\section{Chapter 4. Human rights}

This important part of the draft outlines the human rights of people with mental disorders, such as the right to medical care. It covers consent to treatment if capacity is impaired. It states the importance of patients' privacy and their right to make complaints about the care they receive. It also states the right of patients to have legal advocates to represent them.

\section{Chapter 5. Hospital admissions}

This chapter defines the two types of admission to psychiatric hospital, voluntary and compulsory.

\section{Voluntary admission}

If adults aged 18 or more have been assessed and it is decided that they need hospital admission, they should be asked whether they agree to it or not. They have the right to leave or discharge themselves at any time, unless there are grounds for compulsory detention.

\section{Compulsory admission}

If a patient refuses voluntary admission and there is evidence of a severe mental disorder, compulsory admission may be appropriate in any of the following further circumstances: the mental disorder 
requires hospital treatment; admission is in the interest of the patient's health or safety; or admission will serve the protection of others. The draft Act states that a recommendation for compulsory detention can come from: one of the patient's relatives; the police; social workers; or an ambassador where a foreign national is to be admitted.

The on-call psychiatric doctor (no specific qualifications are mentioned to define a psychiatric doctor) can detain people against their wishes, for up to 1 week, if they refuse voluntary admission, provided there are signs of a mental disorder that warrants treatment in hospital, or there is risk to the patient or to others.

Thereafter, the responsible medical officer (a consultant) can either discharge the patient or extend the period of detention by 1 month. If the patient needs to stay longer in hospital, the consultant can extend the period of detention for a further 3 months but has to submit a report to the hospital administration or the health authority to outline the reasons behind that decision.

If, after the 3 months, the patient needs to be detained for longer still, then a decision will be taken by the multidisciplinary team rather than the consultant alone. Compulsory admission can then extend for a maximum of 6 months, which can be renewed again for another 6 months, and so forth.

\section{The right to appeal}

Patients who are compulsorily admitted to hospital will have the right to appeal against their detention. A second opinion from a different psychiatric team will have to be sought regarding the appropriateness of the detention.

This part was missing from the original draft and was later added as suggested by the Sudanese Psychiatrists Association (UK and Ireland), reflecting their experience of using the Mental Health Act in the UK.

\section{Chapter 6. Psychiatric treatment}

This chapter stresses the importance of delivering the accepted therapeutic interventions through an integrated and comprehensive care plan for each patient, in consultation with both the patient and family. The mental health team may grant the patient a period of leave outside the hospital grounds if appropriate.

In relation to treatment, the draft legislation stipulates that psychiatric institutions should follow widely accepted treatment options and guidelines. It specifically mentions that 'each patient should have a care plan tailored to his/her needs' and that 'treatment should be given only with the consent of the patient, except for detained patients'.

\section{Chapter 7. Responsibilities of mental health professionals}

Health professionals cannot be held legally responsible for detaining a patient or providing compulsory treatment. However, they can be held accountable for their actions if there is evidence of a gross misconduct or negligence.

\section{Discussion}

Some points in the draft need further clarification.

First, there is no specific mention of the use of either electroconvulsive therapy (ECT) or seclusion. Nor is there mention of treatment in the community.

No clear mechanisms have been set out for the resolution of any conflicts that may arise between the treating team and the patient's family. This is particularly important in Sudan, where mental illness is considered a stigma, or 'evil doing' that needs to be dealt with by religious healers. Families may therefore object to compulsory detention and the draft does not mention what the treating team can do in such circumstances.

In Chapter 5 it is mentioned that the treating team has the power to detain a patient for up to 6 months (see above); however, it is not clear what types of professionals need to be members of this team (its skill mix of doctors, nurses, social workers, psychologists and so on). Also, there is no clear mechanism for the resolution of any disagreement among members of the team if they fail to reach one opinion about the detention of a patient.

The procedures for appeal are not clear. Although the draft Act states that patients can be assessed by a 'different team' if they appeal against detention, it is not clear, for example, whether that team should be from the same hospital or from a different one.

Most importantly, the implementation of the legislation will add to the demands on limited resources. Most psychiatrists practise in Khartoum and the big cities only. There are whole provinces where there is only one psychiatrist, or none at all, and it is not clear how compulsory detention can be applied in such circumstances. This needs further discussion.

To ensure proper application of the Act, mental health workers should be offered appropriate training on its provisions. It is not clear who would be responsible for the training.

Finally, clear safeguards and appeal mechanisms should be in place to ensure patients' relatives or the authorities do not abuse the new Mental Health Act.

\section{Conclusion}

Despite shortfalls and gaps in the draft Act, it is our opinion that this is a major step towards the reform of mental health practice in Sudan and should be praised and supported. It is our understanding that legal experts will review the draft before it is submitted to Parliament.

We will continue to work hard with our colleagues in Sudan to improve and to implement the draft Mental Health Act, which will be the first such legislation in Sudan. Without it, Sudanese patients with mental illnesses will continue to be vulnerable and mistreated. 